\title{
TEXTILES, COLOUR CHEMISTRY AND DYEING AT LEEDS
}

\begin{abstract}
WHE report to the Worshipful Company of Clothworkers of the City of London of the Advisory Committee on the Departments of Textile Industries and Colour Chemistry and Dyeing in the University of Leeds for the session 1960-61 covers the eightyseventh session of the former*. During this period the number of students fell slightly to 377 , and 56 students obtained higher degrees, postgraduate diplomas and degrees, and 26 were awarded diplomas. In textile physics, work on the $\alpha \beta$-transformation in keratin continued, a method of evaluating the 'crystallinity' of keratin by quantitative assessment of X-ray scatter, was evolved which provides a useful standard of reference for other methods, and interesting differences in fine structure between wools of different quality were recorded. In textile chemistry studies of the by-products of the fleece continued, and work on the constitution of the resin acids of wool has indicated that they are, for the most part, not acids but polar auto-oxidation products of the alcohols. Filaments with properties very similar to ordinary viscose rayon have been produced. by a wet-spinning process from a derivative of pectin. Investigations of the polymerization of methacrylic acid within nylon have shown that the polymer is cross-linked, and following studies of the sorption of methacrylic acid from aqueous fibres by nylon 66 fibres, work has been started on the general acidcombining properties of nylon and related materials. In textile engineering the theory explaining the

* Report to the Worshipful Company of Clothworkers of the City of London of the Advisory Committee on the Departments of Textile Industries and Colour Chemistry and Dyeing in the University of Leeds for the Session 1960-61. Pp. 48. (Leeds: The University,
1962.)
\end{abstract}

transmission of sound among the looms in a weaving shed has been elaborated, confirmed by measurement and applied to predict the diffuse sound-levels to be found and the broad variations to be expected in industrial weaving sheds. In textile technology, the performance and design of knitting machine mechanisms, relations between structure and properties of woven fabrics and fundamental principles underlying textile finishing operations have been investigated, as well as the effects of chemical treatments on the surface characteristies of fibres. It has been demonstrated that oxidized wool fibres can be set in a solution of tetrakis (hydroxymethyl) phosphonium chloride but not in water.

In the Department of Colour Chemistry and Dyeing, which is in its eighty-second session, there were 46 undergraduate students and 15 research workers. Work was continued on the kinetic and thermodynamic aspects of dyeing from the vapour phase, on the mechanism of formation of dioxazine dyes, the chemistry of $1: 1^{\prime}$-dinaphthyl and perylene, the reactions of $9: 10$ benzomesobenzanthrone and the measurement of changes of hue of azo pigments resulting from closely controlled changes in the conditions of coupling, as well as the study of solventassisted dyeing and printing processes. An investigation of the isomers of indanthrone was completed and also work on the kinetic and thermodynamic aspects of dyeing cellulose acetate rayon with sulphated dyes, and on the effect of chemical structure of a group of related 2: 1 metal-complex dyes on their dyeing behaviour in presence and absence of solvents. Lists of publications during the year are included in both reports.

\section{GEOMAGNETIC DISTURBANCES ASSOCIATED WITH THE NUCLEAR EXPLOSION OF JULY 9}

\author{
By DR. P. R. PISHAROTY \\ India Meteorological Department, Colaba Observatory, Bombay
}

\begin{abstract}
$\mathrm{T}$ HE geomagnetic observatories at Annamalainagar (geographically $11^{\circ} 24^{\prime}$ N.; $79^{\circ} 41^{\prime}$ E.; geomagnetically $1.8^{\circ} \mathrm{N} . ; 149 \cdot 4^{\circ} \mathrm{E}$.) and Trivandrum (geographically $8^{\circ} 29^{\prime} \mathrm{N}$.; $76^{\circ} 57^{\prime}$ E.; geomagnetically $0 \cdot 9^{\circ}$ S.; $146 \cdot 3^{\circ}$ E.) have recorded marked changes in the Earth's field around 09 h U.T. on July 9, 1962. These are reproduced in Fig. 1. A megaton nuclear charge was exploded at this time at a height of $320 \mathrm{~km}$ over Johnston Island (geographically $16^{\circ} 42^{\prime}$ N.; $169^{\circ} 24^{\prime}$ W. ; geomagnetically $14 \cdot 3^{\circ}$ N.; $265 \cdot 5^{\circ}$ E.). The changes at the two stations are similar in type and somewhat resemble a magnetic storm on a much smaller scale. The disturbance in $H$ consists of a positive sudden commencement (detectable in the originals), an extremely short initial phase if any, and a main phase in which the $H$ value is depressed below the normal-the total duration being about $12 \mathrm{~min}$ at both the stations. The details of the changes are given in Table 1 . Those in the magnetograms at Alibag (geographically $18^{\circ} 38^{\prime}$ N.; $72^{\circ} 52^{\prime}$
\end{abstract}

E.; geomagnetically $9.5^{\circ} \mathrm{N} . ; 143.6^{\circ}$ E.) are very much less, the most noteworthy feature at this place being an oscillation motion in the $D$-trace, similar to what happens when lightning flashes occur near the station. All these changes are apparently a direct consequence of the injection into the exosphere of a large amount of protons and helium nuclei produced by the explosion.

Atomic blasts at ground-level have been found to have no effect on normal-run magnetograms ${ }^{2}$. The atomic explosion ten miles or so above ground, of the

\begin{tabular}{|c|c|c|c|c|}
\hline \multirow{3}{*}{$\begin{array}{c}\text { Stations } \\
\text { Annamalainagar } \\
\mathbf{1 \cdot 8 , 1 4 9 \cdot 4}\end{array}$} & \multirow[b]{2}{*}{ Duration } & \multicolumn{3}{|c|}{ Maximum change in } \\
\hline & & $\bar{H}$ & $\bar{\nabla}$ & $D$ \\
\hline & $12 \mathrm{~min}$ & $-30 \gamma$ & $-3 \gamma$ & $\begin{array}{l}0 \cdot 60^{\prime} \text { (with superposed } \\
\text { feeble oscillations) }\end{array}$ \\
\hline $\begin{array}{l}\text { Trivandrum } \\
-0 \cdot 9,146 \cdot 3 \\
\text { Alibag } \\
9 \cdot 5,143 \cdot 6\end{array}$ & $\begin{array}{l}12 \mathrm{~min} \\
12 \mathrm{~min}\end{array}$ & $\begin{array}{l}-38 \gamma \\
-8 \gamma\end{array}$ & $\begin{array}{l}-40 \gamma \\
+\quad 2 \gamma\end{array}$ & $\begin{array}{l}\text { Feeble oscillations } \\
\text { Oscillations well marked }\end{array}$ \\
\hline
\end{tabular}

